\title{
Fluctuations du peuplement hongrois depuis un millénaire
}

Hungarian settlements during the last millennium

Entwicklung der ungarischen Siedlung seit tausend Jahren

\section{Károly Kocsis}

\section{OpenEdition}

Journals

Édition électronique

URL : http://journals.openedition.org/rge/1790

DOI : $10.4000 /$ rge. 1790

ISSN : 2108-6478

\section{Éditeur}

Association des géographes de l'Est

Édition imprimée

Date de publication : 1 janvier 2003

ISSN : 0035-3213

Référence électronique

Károly Kocsis, "Fluctuations du peuplement hongrois depuis un millénaire », Revue Géographique de l'Est [En ligne], vol. 43 / 1-2 | 2003, mis en ligne le 01 décembre 2010, consulté le 07 septembre 2020. URL : http://journals.openedition.org/rge/1790 ; DOI : https://doi.org/10.4000/rge.1790

Ce document a été généré automatiquement le 7 septembre 2020

Tous droits réservés 


\title{
Fluctuations du peuplement hongrois depuis un millénaire
}

\author{
Hungarian settlements during the last millennium \\ Entwicklung der ungarischen Siedlung seit tausend Jahren
}

Károly Kocsis

\section{NOTE DE L'ÉDITEUR}

Cet article a été adapté et mis en forme par Stéphane Rosière et Simon Edelblutte (CERPA / Université Nancy 2).

\section{Introduction}

1 Il n'existe guère de nations européennes dont l'effectif et l'aire de peuplement aient varié de manière aussi importante au cours du dernier millénaire que la nation hongroise. En considérant la dynamique de son aire de peuplement - ses multiples agrandissements et rétrécissements - le cas hongrois ne peut être comparé qu'avec celui des Croates et des Polonais. Les Croates, dans la période allant du XV siècle au XVIII ${ }^{\mathrm{e}}$ siècle, vivaient en effet dans la zone privilégiée de l'affrontement entre Chrétiens et Ottomans, leur aire de peuplement en a été profondément et fréquemment remaniée. Quant aux Polonais, ils ont subi le même sort dans la zone d'affrontement de la Russie et de l'Allemagne.

2 Les changements fréquents de la composition ethnique de l'espace hongrois sont à mettre en corrélation avec la situation géographique de leur habitat: le bassin des Carpates. Ce bassin, autour duquel se love la chaîne du même nom, se trouve, d'une part dans la zone de contact entre la Chrétienté occidentale (catholique romaine), la Chrétienté orientale (orthodoxe) et l'Islam (et cela du XVe au XIX siècle) et, d'autre part, entre les blocs ethniques slave, germanique, roumain et hongrois. Cette 
localisation géographique explique à la fois l'influence majeure des grands événements historiques européens sur la Hongrie, la taille et les limites des territoires de peuplement hongrois ainsi que le mode de vie de la population.

3 Cette évolution de la composition ethnique du bassin des Carpates est abordée dans cet article de façon chronologique, en privilégiant 6 dates essentielles de l'histoire de l'Europe centre-orientale et plus particulièrement de celle de la Hongrie : 896, 1526, 1711, 1849, 1920, 1944.

\section{De l'arrivée des Hongrois dans le bassin des Carpates à la domination des Habsbourg}

\section{A. De 896 à 1526}

Lorsqu'ils se sont établis dans le bassin des Carpates à partir de 896, les Hongrois étaient entre 150000 et 400000 . Ce territoire comptait alors environ 200000 habitants d'origine slave (Slavons, Slovènes, Moraves, Carantans, Croates Blancs, Bulgares, etc.) et avar (Gyırffy, 1995 ; Kovácsics, 1995 ; Kristó, 1995). Les Hongrois se sont alors établis dans les régions convenant le mieux à leur mode de vie semi-nomade et ressemblant à l'environnement naturel de leur précédent habitat: prairie et steppe adaptées au pâturage, vallées stratégiques mais aussi pays de collines à couverture forestière dominée par le chêne (fig. 1).

Figure 1 : Le peuplement hongrois dans le bassin des Carpates au Xle siècle.

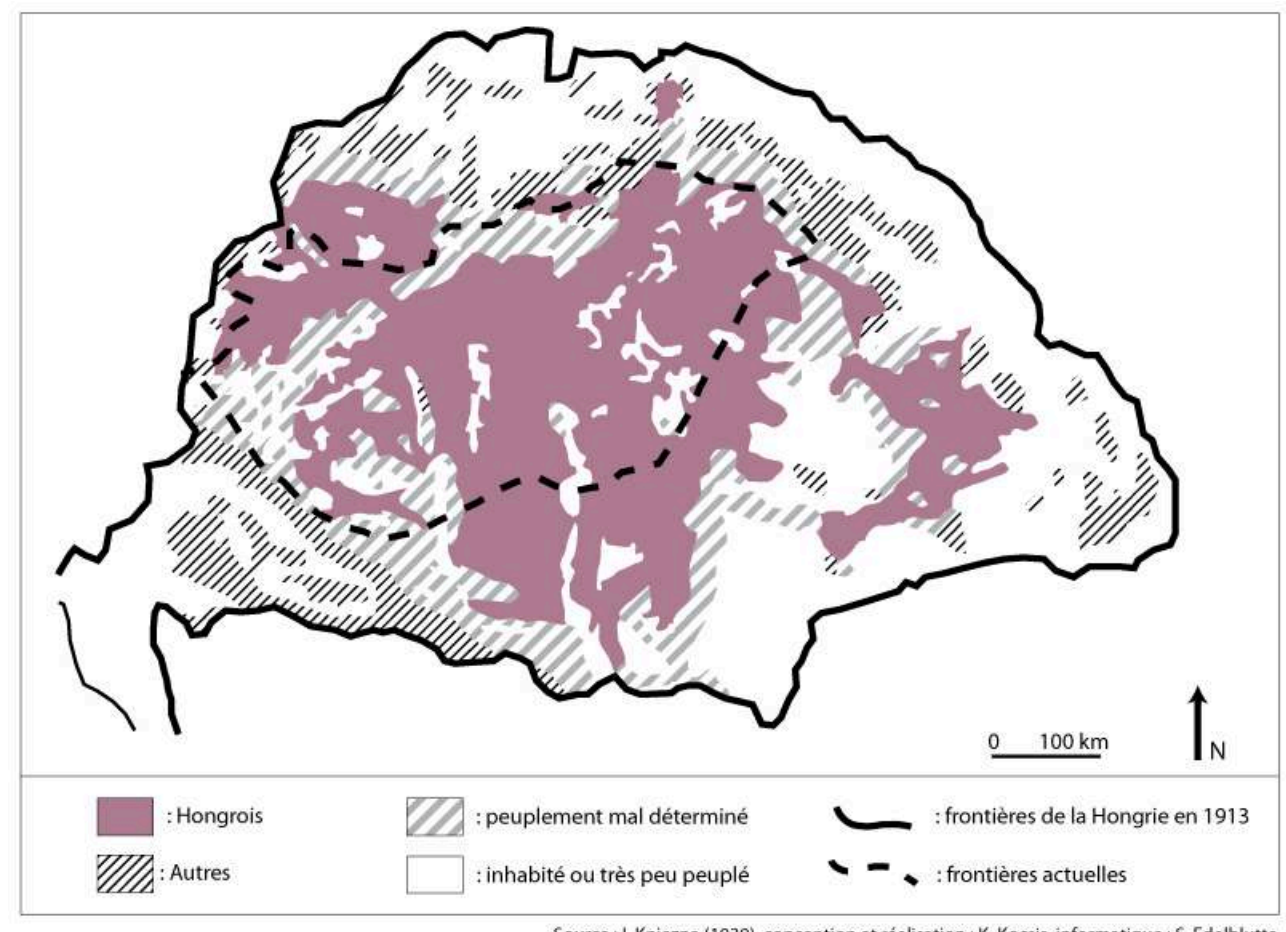

Source : I. Kniezna (1939), conception et réalisation : K. Kocsis, informatique : S. Edelblutte

5 Par la suite, le peuplement hongrois du bassin est devenu assez homogène, notamment à partir du XVe siècle et en raison de l'assimilation progressive de nombreuses ethnies : Slaves, Petchénègues disséminés, Coumanes, Iazyges; ces derniers, établis après l'invasion tatare, disposaient d'une autonomie territoriale en contrepartie de leur 
allégeance militaire. Grâce à ces assimilations, le peuple hongrois, malgré les pertes subies face aux invasions tatares, a atteint, au tournant des $\mathrm{XV}^{\mathrm{e}}$ et $\mathrm{XVI}^{\mathrm{e}}$ siècles, 3,2 millions de personnes, c'est-à-dire plus que le nombre d'Anglais et de Gallois réunis (2 millions). Les Hongrois représentaient alors $80 \%$ de l'effectif total de la population du bassin des Carpates, estimée à 4 millions de personnes (Mályusz, Szabó, 1941). La frontière linguistique hongroise s'étendait d'une manière générale trente kilomètres plus loin que la frontière actuelle, notamment en Slovaquie et en Ukraine transcarpatique ${ }^{1}$ (Kniezsa, 1938, 1939).

En Transylvanie, alors majoritairement peuplée de Hongrois, le peuplement des

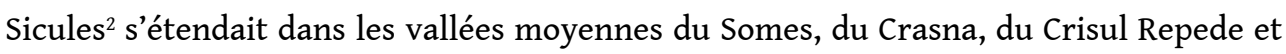
du Mures. L'aire de peuplement hongrois formait ainsi un bloc continu depuis la grande plaine hongroise jusqu'au plateau transylvain (fig. 2). Plus au Sud du bassin des Carpates, les plaines et les collines du Banat, la Batchka dans son ensemble, la partie nord de la Syrmie (Srem) et la région d'Osijek et Vukovar (Slavonie orientale) ${ }^{3}$ étaient aussi peuplées en majorité de Hongrois. Dans ces régions méridionales, qui au $\mathrm{XV}^{\mathrm{e}}$ siècle avaient encore une activité économique florissante et une forte densité de population, le nombre de Hongrois a néanmoins significativement diminué en raison, d'une part des guerres paysannes de 1514 et des représailles qui les suivirent, et, d'autre part, des rafles continues opérées par les Turcs. De plus, à partir des années 1520, l'arrivée incessante de réfugiés Serbes fuyant les Trucs et franchissant le Danube pour se réfugier dans le royaume de Hongrie, a eu pour effet de rendre plus hétérogène le peuplement de cette région.

Figure 2 : Le peuplement hongrois dans le bassin des Carpates à la fin du XVe siècle

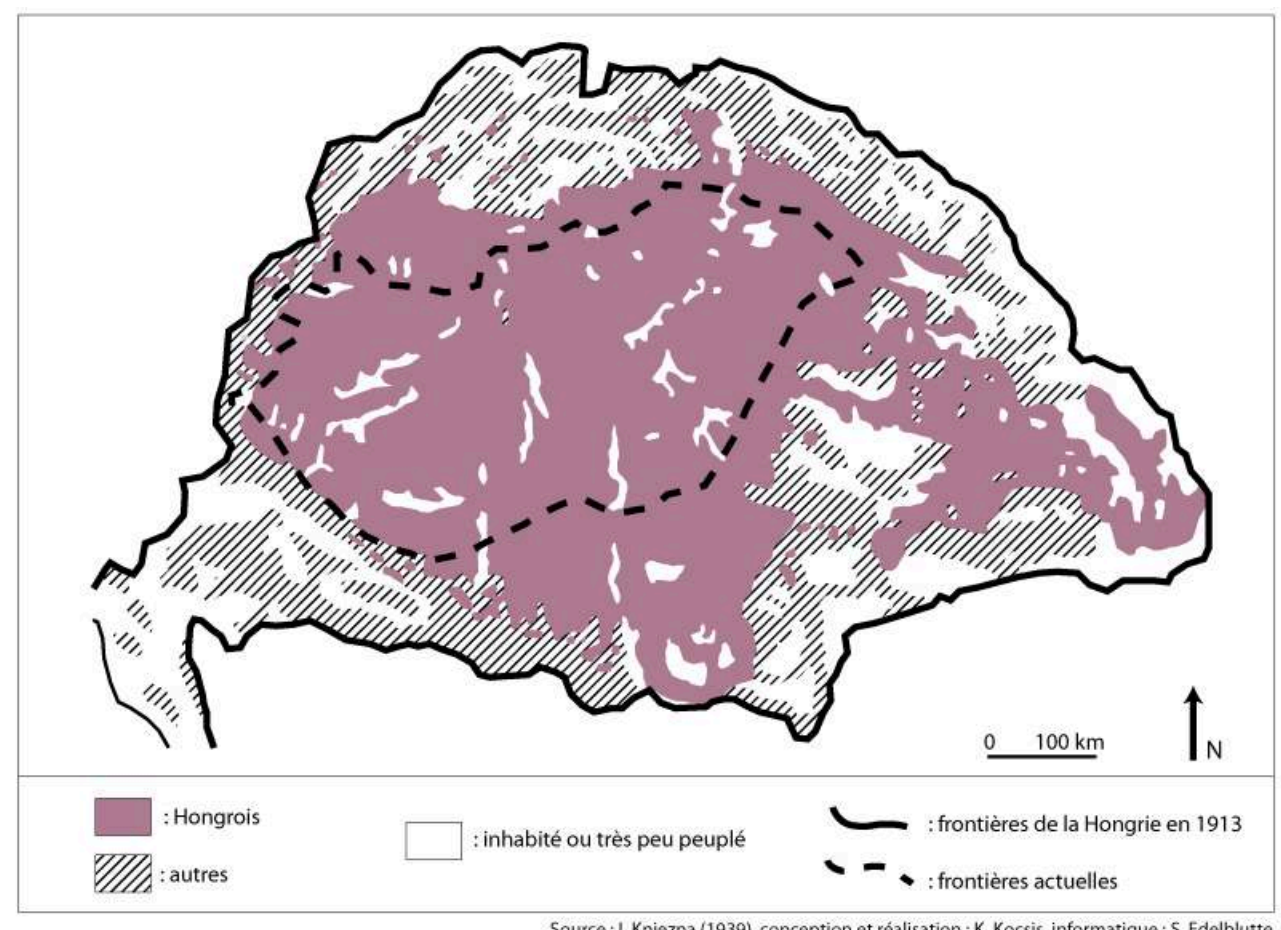

Source: I. Kniezna (1939), conception et réalisation : K. Kocsis, informatique : S. Edelblutte 


\section{B. De 1526 à 1711}

7 La bataille de Mohács en 1526, écrasante victoire turque, a marqué la fin de la Hongrie médiévale, puissance moyenne en Europe centrale. Durant deux siècles, de 1526 à 1711, date de l'échec de la lutte d'indépendance contre les Habsbourg, le bassin des Carpates est devenu le théâtre d'une guerre permanente. La composition ethnique de cet espace, peuplé d'une majorité hongroise de $80 \%$ au début du XVI ${ }^{\mathrm{e}}$ siècle, s'en est trouvée définitivement modifiée. Ainsi, le nombre des Hongrois a-t-il baissé de 3,2 millions à 1,5 million tandis que les autres groupes ethniques connaissaient au contraire une forte progression, passant de 1 million à 1,7 million (Szabó, 1941). Dans les régions du sud (Banat, Batchka, Syrmie et Slavonie) et notamment dans la zone frontalière de l'empire turc (appelée zone militaire), la population hongroise a presque entièrement disparu. À la même époque, un phénomène de forte baisse a aussi existé dans d'autres régions comme le bassin de Transylvanie, le centre de la Grande Plaine ou la partie sud de la Transdanubie.

8 Pendant la domination turque - qui a duré 150 ans - la continuité étatique hongroise a néanmoins été maintenue par la Principauté de Transylvanie, état aux frontières très changeantes et dont la population hongroise a subi les persécutions du général habsbourgeois Giorgio Basta (1599-1604) puis du voïvode roumain Michel le Brave. En outre, les expéditions militaires turques et tatares (1657 et 1661) ont causé d'énormes ravages dans la population et ont abouti à la décomposition et à la segmentation du territoire peuplé par les Hongrois, notamment dans les vallées moyennes du Somes, du Crasna, du Crisul Repede et du Mures, soit en plein centre de la Transylvanie. Par conséquent, à partir de la deuxième moitié du XVII ${ }^{\mathrm{e}}$ siècle, la population hongroise est devenue moins nombreuse en Transylvanie que la population roumaine sans cesse croissante. Cette évolution s'explique notamment par le fait que les Roumains (ou Valaques) vivaient jusqu'alors surtout dans les zones montagneuses, défavorisées d'un point de vue économique, mais laissées plus à l'écart des conflits que les vallées et leurs villes, peuplées par les Hongrois. Ces vallées, en tant que couloirs de circulation fondamentaux, ont particulièrement été ravagées par les armées en mouvement. Par ailleurs, le dynamisme démographique des Valaques de Transylvanie était aussi soutenu par une immigration en provenance de Valachie et de Moldavie, zones planes plus exposées aux Turcs. Ainsi et alors qu'en 1495, la Transylvanie comptait $53 \%$ de Hongrois pour $22 \%$ de Roumains, elle en comptait, en 1720 , respectivement $22 \%$ et $49,6 \%$, les proportions s'étant pratiquement inversées... (Kocsis, 1997).

\section{De la domination des Habsbourg au traité de Trianon}

\section{A. De 1711 à 1849}

9 Avec la fin de la domination ottomane, s'est amorcée, dans le bassin des Carpates, une redistribution spatiale des groupes ethniques tous réunis politiquement sous l'autorité des Habsbourg. Des Hongrois venant des périphéries du bassin se sont alors installés dans la Grande Plaine hongroise (Alföld), et notamment au centre de celle-ci : Petite et Grande Coumanie, comitat de Csongrád. Ces territoires étaient en effet 
dépeuplés depuis les guerres turques et, par exemple, la région de l'Hortobágy avait été totalement vidée de toute population. Cependant, la fertilité élevée de leurs sols les rendait attractifs et un mouvement de population, essentiellement composé de serfs évadés s'émancipant dans ces terres redevenues "vierges", a repeuplé ces territoires. Ces mouvements migratoires ont eu pour effet une plus grande concentration spatiale des Hongrois et ont assuré la renaissance d'un bloc territorial hongrois continu, comme cela fut seulement le cas au moment de la conquête du pays en 896, ou encore après l'invasion tatare de 1241-1242.

Pendant les guerres turques, des milliers de Slovaques, de Ruthènes et de Roumains se sont eux aussi déplacés vers les régions de plaine vidées de leur population hongroise, formant ainsi des îlots linguistiques dispersés à l'intérieur du bloc ethnique hongrois. Le XVIII ${ }^{e}$ siècle a donc eu pour résultat une hétérogénéité ethnique et religieuse croissante dans certaines régions du bassin des Carpates. Outre ces mouvements plus ou moins spontanés, il faut également mentionner les vagues de colonisation organisées par les Habsbourg pour reconstruire les villes et redresser les régions dévastées (Banat). Cette politique de colonisation prenait en considération des aspects économiques, ethniques et religieux. Elle favorisait ainsi l'établissement d'une population, les Souabes, généralement germanophone et toujours catholique. En revanche, les Habsbourg ont bloqué le repeuplement par des populations hongroises ou protestantes pendant plusieurs décennies, en particulier dans les régions du Sud. Ainsi, en Voïvodine, les Habsbourg favorisaient l'établissement de Serbes au détriment de Hongrois.

11 Ces grands mouvements migratoires du XVIII e siècle ont induit un changement de la composition ethnique de la population du bassin des Carpates. La population totale du bassin est passée, au cours de ce siècle, de 4,3 millions à 9,9 millions (+ $130 \%)$. Dans ce total, les Hongrois sont passés de 1,7 million à 3,1 millions $(+82 \%)$. Les autres ethnies ont largement mieux progressé passant, grâce à l'immigration de plus de trois millions de personnes (Allemands et Serbes surtout, mais aussi Roumains et Ruthènes), de 2,6 millions à 6,8 millions, soit + $161 \%$ (Wellman, 1988 ; Kovács, 1920 ; Szabó, 1941). En conséquence, la proportion des Hongrois par rapport aux autres nationalités a baissé à un niveau très bas, atteignant seulement $31,5 \%$ de la population totale niveau qui n'avait jamais été observé auparavant (en $1500: 80 \%$, en $1720: 40,7 \%$ ). Le territoire peuplé de Hongrois s'est donc rétracté de manière significative et s'est trouvé dès lors divisé en deux parties : un vaste ensemble centré sur la Hongrie actuelle, et un autre plus petit constitué par le Pays Sicule en Transylvanie orientale (fig. 3). Néanmoins, dans les zones rurales, la frontière ethnolinguistique hongroise s'est lentement stabilisée et n'a pas changé de manière significative avant la fin du XVIII ${ }^{e}$ siècle. 
Figure 3 : Le peuplement hongrois dans le bassin des Carpates en 1777

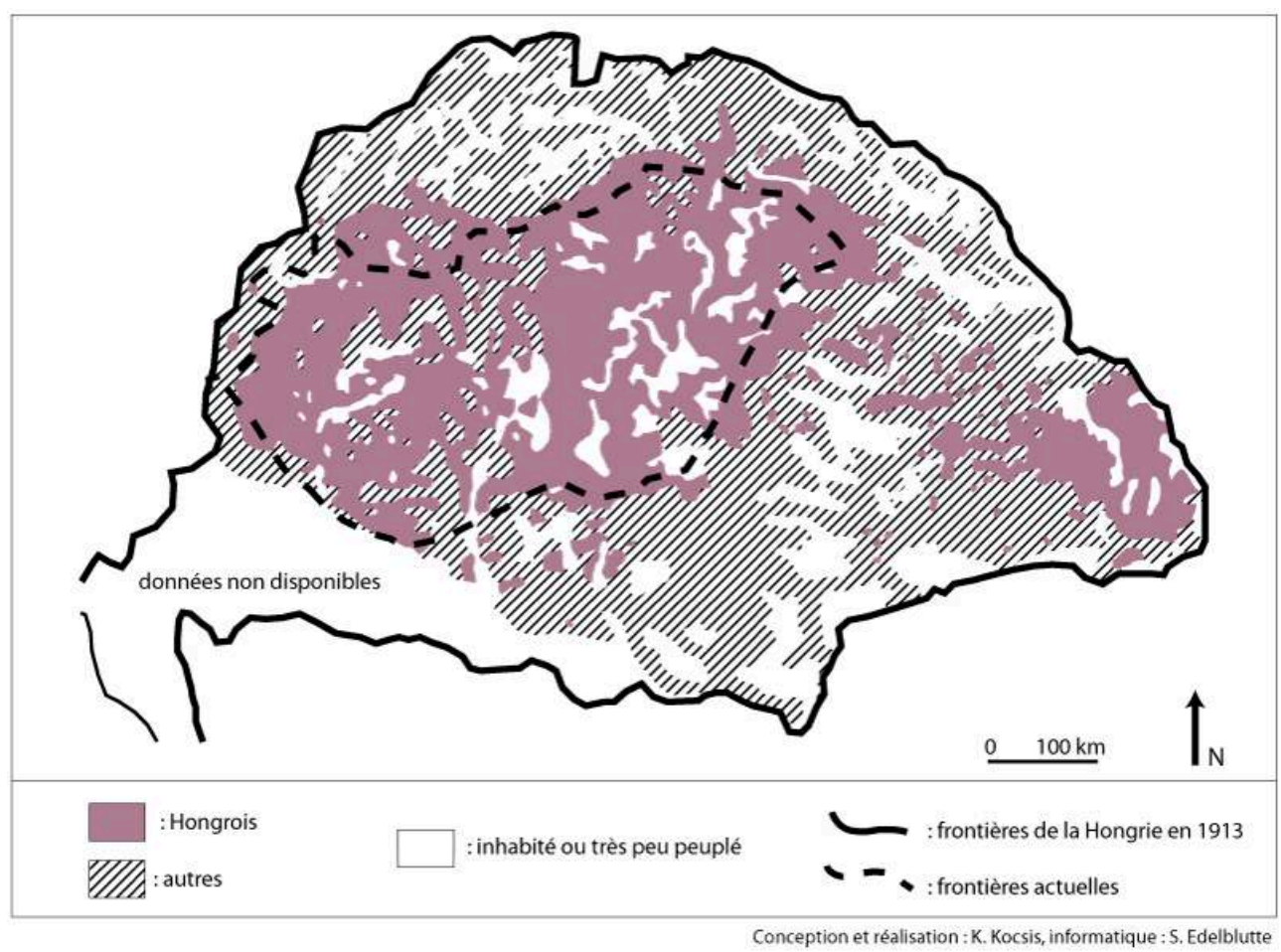

Avec les prémices de l'exode rural et le ralentissement des actions de colonisation pendant le XIX ${ }^{e}$ siècle, la population hongroise - établie dans les zones centrales et sur des terres favorables à la production agricole - s'est accrue trois fois plus rapidement que les autres. Ainsi est elle passé, dans le bassin des Carpates, de 3,1 millions en 1790 à 4,8 millions à la veille de la révolution de 1848 (Fényes, 1842), représentant respectivement 31,5 et $37,4 \%$ de la population totale du bassin. Cet accroissement de la population hongroise au milieu du siècle n'a été interrompu que lors de la guerre d'indépendance $(1848 / 49)^{4}$ qui, si elle fut relativement brève, se caractérisa néanmoins par de lourdes pertes.

\section{B. De 1849 à 1920}

En 1850, et selon un recensement autrichien effectué après l'échec de la guerre d'indépendance, le nombre des Hongrois n'avait pas tellement changé par rapport celui de 1840 (4,8 millions). Par contre, il atteignait 6,4 millions en 1880 et dépassait 10 millions en 1910, représentant respectivement 41,2 et $48 \%$ de la population totale du bassin des Carpates (tableau 1). Cet important accroissement des Hongrois, certes lié au Compromis austro-hongrois de 1867, n'a pas été la conséquence d'une magyarisation forcée de la part d'un gouvernement hongrois plus autonome par rapport à Vienne, puisqu'il s'est effectué en partie avant ce compromis. Avant et après 1867 - et jusqu'à la Première Guerre Mondiale - le peuplement hongrois du bassin a donc été favorisé, d'abord par un taux de natalité plus élevé des Hongrois, puis, par des mouvements migratoires importants des Non-hongrois. En effet, ces derniers étaient surtout installés dans les régions périphériques qui ne disposaient pas de conditions économiques favorables. Ils ont donc plus souvent émigré que les Hongrois et se sont aussi, par le biais de l'industrialisation, dispersés à l'intérieur du territoire de 
peuplement hongrois, notamment dans les villes, auparavant essentiellement peuplées d'Allemands et de Hongrois. En milieu urbain, ces populations allophones ont été assez rapidement assimilées, surtout après le Compromis de 1867 qui a consacré la domination culturelle et linguistique du Hongrois dans le bassin; l'insertion dans l'ensemble magyar représentait donc, pour les allophones, une chance de promotion sociale.

Tableau 1 : Évolution du nombre des Hongrois entre 1880 et 1990

a. - Dans le bassin des Carpates

\begin{tabular}{|l|c|c|c|c|c|c|}
\hline Années & \multicolumn{2}{|c|}{ Totalité du bassin des Carpates } & \multicolumn{2}{|c|}{ Hongrie actuelle } & \multicolumn{2}{|c|}{ Territoires perdus en 1920 } \\
\hline 1880 & 6419146 & $100 \%$ & 4354613 & $67,8 \%$ & 2064533 & $32,2 \%$ \\
1910 & 10047605 & $100 \%$ & 6730299 & $67,0 \%$ & 3317306 & $33,0 \%$ \\
1930 & 10650737 & $100 \%$ & 8000335 & $75,1 \%$ & 2650402 & $24,9 \%$ \\
1941 & 11912284 & $100 \%$ & 8655798 & $72,7 \%$ & 3256486 & $27,3 \%$ \\
1949 & 11547626 & $100 \%$ & 9076041 & $78,6 \%$ & 2471585 & $21,4 \%$ \\
1960 & 12567714 & $100 \%$ & 9786038 & $77,9 \%$ & 2781676 & $22,1 \%$ \\
1970 & 12969985 & $100 \%$ & 10166237 & $78,4 \%$ & 2803748 & $21,6 \%$ \\
1980 & 13412752 & $100 \%$ & 10579898 & $78,9 \%$ & 2832854 & $21,1 \%$ \\
1990 & 12929048 & $100 \%$ & 10225529 & $79,1 \%$ & 2703519 & $20,9 \%$ \\
\hline
\end{tabular}

b. - Dans les territoires perdus par la Hongrie en 1920

\begin{tabular}{|l|c|c|c|c|c|c|c|}
\hline Années & Slovaquie & $\begin{array}{c}\text { Transcarpathie } \\
\text { (Ukraine) }\end{array}$ & $\begin{array}{c}\text { Transylvanie } \\
\text { (Roumanie) }\end{array}$ & $\begin{array}{c}\text { Voïvodine } \\
\text { (Serbie) }\end{array}$ & Croatie & $\begin{array}{c}\text { Prekomurje } \\
\text { (Slovénie) }\end{array}$ & $\begin{array}{c}\text { Burgenland } \\
\text { (Autriche) }\end{array}$ \\
\hline 1880 & 574862 & 105343 & 1045098 & 265287 & 49560 & 13221 & 11162 \\
1910 & 881320 & 185433 & 1658045 & 425672 & 119874 & 20737 & 26225 \\
1930 & 585434 & 116548 & 1480712 & 376176 & 66040 & 15050 & 10442 \\
1941 & 761434 & 233840 & 1711851 & 465920 & 64431 & 16510 & 2500 \\
1949 & 354532 & 139700 & 1481903 & 428554 & 51399 & 10246 & 5251 \\
1960 & 518782 & 146247 & 1616199 & 442560 & 42347 & 9899 & 5642 \\
1970 & 552006 & 151949 & 1625702 & 423866 & 35488 & 9064 & 5673 \\
1980 & 559801 & 158446 & 1691048 & 385356 & 25439 & 8617 & 4147 \\
1990 & 567296 & 155711 & 1604266 & 339491 & 22355 & 7637 & 6763 \\
\hline
\end{tabular}

sources : recensements hongrois (langue maternelle) : 1880-1910; tchécoslovaques et slovaques (ethnicité) : 1930, 1941, 1950, 1961, 1970, 1980, 1991 ; soviétiques (ethnicité) : 1950, 1959, 1970, 1979, 1989 ; roumains (langue maternelle) : 1930, 1941, 1948, 1956, 1966 ; roumains (ethnicité) : 1977, 1992 ; yougoslaves (langue maternelle) : 1931 ; yougoslaves (ethnicité) : 1948, 1961, 1971, 1981, 1991 ; autrichiens (Umgangssprache : langue vernaculaire) : 1934, 1951, 1961, 1971, 1981, 1991.

14 L'importante homogénéisation de la population urbaine a eu pour résultat qu'en 1910, $77,5 \%$ des citadins du Royaume de Hongrie se considéraient comme Hongrois et que $88,9 \%$ pouvaient parler hongrois. Le cas de Budapest illustre parfaitement cette situation, puisque la proportion des habitants de la ville se déclarant hongroise est passée de 56,8 \% à 85,9\% entre 1880 à 1910 . Ce renforcement a donc été principalement le résultat d'une magyarisation spontanée et a surtout concerné les couches sociales les plus élevées. Parmi la classe intellectuelle du pays - 300700 personnes à l'époque $82,3 \%$ se considéraient Hongrois, 8,6\% Allemands, 4,3\% Roumains et 1,5\% Slovaques (Kovács, 1925). Par ailleurs, la spectaculaire assimilation des Juifs a renforcé la part des Hongrois dans la classe dirigeante économique et financière (84,5 \%).

Naturellement, ce processus favorable aux Hongrois n'a pas concerné les différentes nationalités de la même façon. Sur environ 2 millions de personnes "magyarisées » dans la période 1848/49-1914, plus d'un tiers étaient des Juifs, un quart des Allemands, et un cinquième des Slovaques (Katus, 1988). Dans les dernières décennies de la monarchie austro-hongroise et dans presque tous les domaines de la vie sociale, les 
nationalités non-hongroises ont été poussées à l'arrière-plan au profit des Hongrois. Cette situation défavorable a généré un fort ressentiment chez les élites non-hongroises et a justifié l'importance des revendications anti-hongroises au lendemain de la Première Guerre Mondiale.

\section{Du traité de Trianon à aujourd'hui}

\section{A. De 1920 à 1944}

16 À la fin de la première Guerre Mondiale et par le traité de Trianon signé le 4 juin 1920, les puissances victorieuses de l'Entente, en satisfaisant les exigences les plus exagérées de leurs alliés tchèques, roumains et serbes, ont divisé le territoire de la Hongrie en cinq États également multinationaux. Les deux tiers de la Hongrie historique et un tiers des Hongrois se sont retrouvés dans les États successeurs ${ }^{5}$. Parmi eux, 350000 partirent pour la nouvelle Hongrie née de Trianon entre 1918 et 1924 (Rónai, 1988). À partir de cette période, la situation démographique et le destin des territoires peuplés de Hongrois de part et d'autre de la nouvelle frontière ont suivi des évolutions totalement différentes. En raison de l'atmosphère très négative à l'égard des minorités dans les États successeurs (Hongrie comprise), de la modification des méthodes des recensements - les Juifs n'ayant par exemple plus le droit de se déclarer Hongrois de l'assimilation et des migrations forcées déjà mentionnées, le nombre des Hongrois vivant en dehors de leur État dans le bassin des Carpates a baissé rapidement de 3,3 (1910) à 2,6 millions (1930). Le territoire de peuplement hongrois a donc reculé par rapport a celui de 1910 dans les villes situées sur les différentes frontières linguistiques. Tel a été le cas, en Tchécoslovaquie de Nitra, Levice, Komárno, Kosice, Trebisov ${ }^{6}$ et Vinogradov ${ }^{7}$; dans les territoires rattachés à la Roumanie, du département de Satu Mare et des villes ayant une importante population allemande et juive, comme Oradea, Arad, Satu Mare, Sighetu, Baia-Mare ou Cluj ; et enfin dans la Batchka yougoslave, de Subotica et de Sombor.

Parallèlement, dans le territoire resté sous administration hongroise, le nombre de Hongrois a augmenté, passant de $88,4 \%$ à $92,1 \%$. Ce phénomène a été la conséquence de l'assimilation naturelle, d'un double mouvement de migrations (de Hongrois vers la Hongrie et inversement de Non-hongrois vers leur État de référence) et de la pression sur les minorités conduisant à une magyarisation accélérée, notamment dans les villes et plus particulièrement à Budapest, où les Hongrois sont passés de 85,9\% en 1910 à 93,9 \% en 1930 (Kocsis, 1994).

18 Pendant l'Entre-deux-guerres, le processus de diminution rapide - en partie réel et en partie seulement statistique car lié à des "désidentifications »- des effectifs des minorités hongroises hors de Hongrie a été enrayé par les révisions territoriales décidées par les deux Accords de Vienne en 1938 et 1941. Ces décisions, prises sous arbitrage italien et allemand, résultaient de considérations tactiques - l'Axe souhaitant un compromis entre ses différents alliés, Hongrie et Roumanie essentiellement - et tenaient mieux compte des limites linguistiques que les frontières de Trianon. En conséquence, les territoires peuplés d'une majorité de Hongrois ont été rattachés à la Hongrie: sud de la Slovaquie, Ruthénie, Nord de la Transylvanie, Batchka (actuelle Serbie), Baranya (actuelle Croatie) et Prekomurje (actuelle Slovénie) (Rónai, 1989). Sur ces territoires rattachés à la Hongrie, le nombre de Hongrois s'est accru de 600000 
par rapport à 1930 en raison du départ de certains Non-hongrois et de la " réidentification " comme Hongrois des Juifs et des personnes à l'identité incertaine (tableau 1). La frontière linguistique, selon le recensement de 1941, s'est ainsi rapprochée de celle de 1910.

Cette situation très favorable aux Hongrois a duré jusqu'à l'occupation du pays par l'Allemagne (19 mars 1944). À partir de cette date, l'internement de la population israélite (725 000 personnes en 1941) a commencé et environ 600000 de ces Juifs hongrois ont été déportés dans les camps Nazis. Ces modifications brutales du peuplement du bassin des Carpates ont contribué à la baisse du nombre des Hongrois, en particulier dans les villes de Ruthénie, Uzgorod, Mukacevo et Beregovo et de Transylvanie du Nord, Satu Mare, Oradea et Cluj.

\section{B. De 1944 à aujourd'hui}

20 En raison des migrations forcées et des déplacements de population organisés par les États dans le cadre de processus de colonisation agraire qui ont duré de 1944 à 1950, plusieurs millions d'habitants du bassin des Carpates ont changé de résidence. En ce qui concerne les Hongrois, ce sont plus de 300000 personnes qui ont suivi l'armée hongroise en retraite ou ont été expulsées des territoires brièvement récupérés par la Hongrie entre 1938 et 1941 . Ces territoires ont été repeuplés de manière autoritaire par les gouvernements des États limitrophes. Ainsi, des centaines de milliers de Slovaques, de Roumains, de Serbes, de Monténégrins, mais aussi des Ukrainiens et, pour la première fois, des Russes ${ }^{8}$, ont été implantés dans les territoires ayant changé de souveraineté durant la guerre. L'objectif essentiel de ces actions de peuplement était la disparition du caractère hongrois de certaines villes, comme Komárno, Nové Zámky, Levice, Lucenec, Kosice, Uzgorod, Mukacevo, Beregovo, Satu Mare, Oradea ou Arad, et de certaines régions situées près des frontières. De cette façon, les États limitrophes de la Hongrie ont tenté de rendre impossible toute exigence révisionniste de la part des Hongrois. Dans ces pays, issus de la Petite Entente', la réussite des projets d'homogénéisation ethnique s'est effectuée au détriment des minorités allemandes, presque entièrement expulsées de Tchécoslovaquie et de Yougoslavie, moins massivement de Hongrie et de Roumanie, mais aussi des minorités hongroises, présentées comme la cinquième colonne du révisionnisme hongrois. Du fait des expulsions et de l'atmosphère très anti-hongroise de cette période, le nombre des Hongrois vivant hors des frontières de Trianon est passé de 3,2 millions en 1941 à 2,4 millions en 1949, selon des statistiques basées sur des déclarations volontaires (tableau 1).

21 Dans les quatre dernières décennies, l'étatisation forcée de la société et la réorganisation de type socialiste de l'économie (nationalisation, collectivisation forcée de l'agriculture, désintégration des cadres traditionnels des communautés villageoises) a augmenté la mobilité géographique de la population. Ceci a eu pour résultat l'arrivée dans les villes - érigées en citadelles de la nouvelle classe ouvrière de plusieurs centaines de milliers de personnes. Ce processus d'urbanisation a naturellement renforcé la proportion des nations dominantes dans chaque État, puisque, très souvent, les différentes minorités nationales vivant en ville depuis des siècles ont été « noyées » sous un flot de nouveaux arrivants. 

du bassin des Carpates se déclarent hongrois (tableau 1). Hors de Hongrie, les Hongrois représentent 2,7 millions de personnes et constituent des zones de peuplement compactes le long des frontières de la Hongrie et dans le Pays Sicule en Transylvanie (fig. 4).

Figure 4 : Le peuplement hongrois dans le bassin des Carpates en l'an 2000.

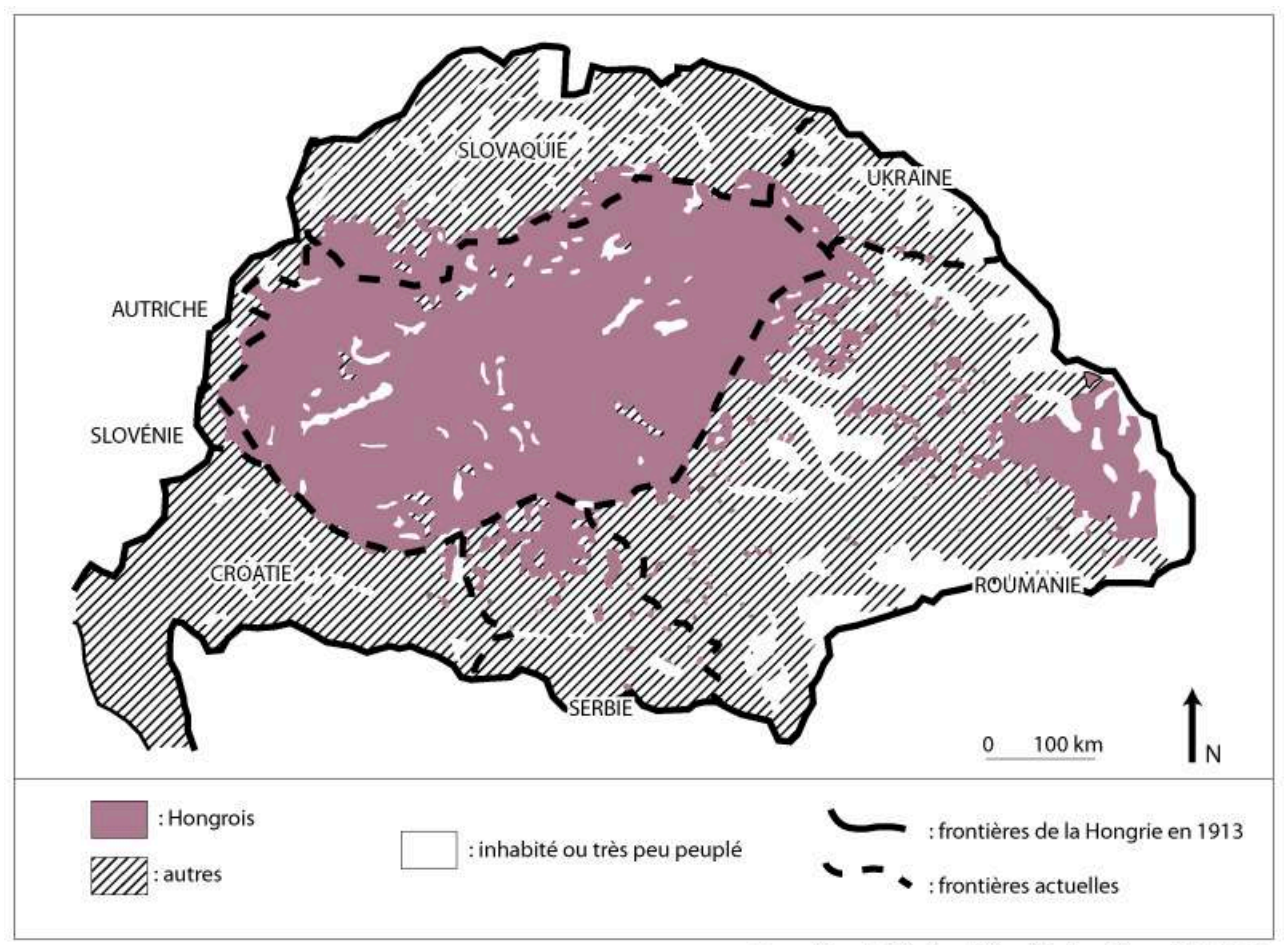

Conception et réalisation : K. Kocsis, informatique : S. Edelblutte 
Cette configuration est le fruit d'une évolution longue de 11 siècles, dans laquelle il est possible de distinguer finalement quatre périodes principales. La première, $\mathrm{du} \mathrm{X}^{\mathrm{e}} \mathrm{au}$ $\mathrm{XV}^{\mathrm{e}}$ siècle, se caractérise par une transgression hongroise, principalement dans les zones inhabitées et, dans une moindre mesure, dans les régions habitées par des Nonhongrois. Dans une deuxième période, $\mathrm{du} \mathrm{XVI}^{\mathrm{e}}$ au XVIII ${ }^{\mathrm{e}}$ siècle, une régression ethnique hongroise très importante est due aux guerres internes, à la domination ottomane, aux luttes de libération et aux mouvements migratoires liés à ces conflits. Dans une troisième période, $\mathrm{du} \mathrm{XIX}^{\mathrm{e}}$ siècle au début $\mathrm{du} \mathrm{XX}^{\mathrm{e}}$, la magyarisation, largement spontanée, conduit à une nouvelle transgression ethnique hongroise, et à une régression des autres nationalités (principalement slovaques et allemandes). Ce processus, s'accélérant au début du XXe siècle, est brutalement stoppé par le traité de Trianon, qui ouvre donc une quatrième phase, encore en cours aujourd'hui et plus contrastée que les précédentes. Le nombre de Hongrois s'accroît en effet dans les frontières de Trianon alors qu'il régresse à l'extérieur, face à la poussée des Slovaques, Ruthènes, Roumaines, Serbes, Croates et Slovènes. Cette phase n'a qu'à peine été atténuée par la courte période de transgression hongroise entre 1938 et 1944.

\section{BIBLIOGRAPHIE}

FÉNYES E. (1842). - Magyarország statistikája (Statistiques hongroises), Tome 1, Pest, 306 p.

Gylrffy Gy. (1995). - A honfoglalók száma és az Árpád-kor népessége (Étude démographique de la Hongrie sous la dynastie Arpád). In : La démographie historique de la Hongrie, Budapest, Office central des statistiques, p. 37-41.

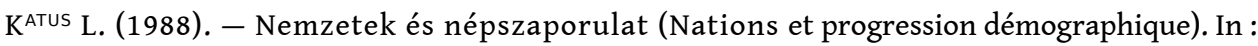
Glatz F. - Éd., Les Hongrois dans le Bassin des Carpates, Budapest, Édition Pallas, p. 171-174.

Kniezsa I. (1938). - Magyarország népei a XI-ik században (Les peuples de la Hongrie au XIe siècle), Budapest, $472 \mathrm{p}$.

Kniezsa I. (1939). - A magyarszág és a nemzetiséget (La Hongrie et les nationalités). In : La Hongrie millénaire, Budapest, Pesti Hirlap RT, p. 91-114.

Kocsis K. (1994). - Budapest és régiója etnikai tészerkezetének átalakulása (Les transformations de la composition ethnique de la région de Budapest entre 1850 et 1990), Földrajzi Értesítı, $\mathrm{n}^{\circ}$ 3-4/43, p. 299-324.

Kocsis K. (1995). - Magyarország etnikai szerkezete (La composition ethnique la Hongrie), Iskolakultura, $\mathrm{n}^{\circ}$ 3-4/5, p. 30-39.

Kocsis K. (1997). - Ethnic map of Transylvania (Carte ethnique de la Transylvanie), Budapest, MTA Institut de Géographie.

Kovács A. (1920). - Magyarország népességének feljldése a török uralom megsz"unte óta (L'évolution de la population hongroise depuis la fin de la domination turque). In : Les négociations de paix entre les Alliés et les Hongrois à Neuilly-sur-Seine en janvier-mars 1920, Budapest, p. 615-630.

Revue Géographique de l'Est, vol. 43 / 1-2 | 2003 
Kovács A. (1925). - Nemzetiségi erlviszonyok a történeti Magyarországon (Les rapports de force entre les nationalités dans la Hongrie historique). In : Dr. Kuno Klebelsberg album, Budapest, p. 615-630.

Kovacsics J. (1995). - A történeti demográfia valaszai és nyitott kérdései az Árpád-kori népesség számára vonatkozóan (Questions et réponses en démographie historique durant la période Arpád). In : La démographie historique de la Hongrie, Budapest, Office central des statistiques, p. 3-36. K RISTÓ Gy. (1995). - Magyarország lélekszáma az Árpád-korban (Le nombre d'habitants en Hongrie sous la dynastie Arpád). In : La démographie historique de la Hongrie, Budapest, Office central des statistiques, p. 42-95.

Mályusz E. (1941). - A magyarság és a nemzetiségek Mohács elltt (Les Hongrois et les nationalités avant 1526). In : Wellman I. - dir. (1988), L'Histoire de la civilisation hongroise, Société hongroise d'Histoire, Budapest.

Rónai A. (1988). - Magyarok elterjedése a Földön (La diffusion des Hongrois dans le monde), Földrajzi Közlemenyék, nº 66, p. 83-104.

R ÓNAl A. (1989). - Térképezett történelem (L’Histoire en cartes), Budapest, Édition Magvetl, 350 p.

Szabó I. (1941). - A nemzetiségek térnyerése és a magyarszág (la transgression des nationalités face au peuple hongrois). In : Wellman I. - dir. (1988), L'Histoire de la civilisation hongroise, Société hongroise d'Histoire, Budapest, p. 111-136.

SZABÓ I. (1941). - A magyarszág életrajza (Biographie du peuple hongrois), Budapest, Société hongroise d'Histoire, $276 \mathrm{p}$.

Wellman I. (1989). - Magyarország népességének fejlldése a 18. században (Le développement de la population de la Hongrie au XVIII ${ }^{\mathrm{e}}$ siècle). In : Histoire de la Hongrie entre 1686 et 1790, Budapest, Éditeur d'Académie, p. 25-80.

\section{Bibliographie complémentaire}

Bakker E. (1998). - Le développement de la population hongroise et son habitat en Slovaquie, Espaces, populations, sociétés, $\mathrm{n}^{\circ}$ 3, p. 417-430.

Rosière S. (1988). - Les minorités magyares d'Europe centrale, Hérodote, n 48, p. 78-106.

Rosière S. (1991). - La Hongrie face au conflit yougoslave, Hérodote, n 63, p. 70-79.

Rosière S. (1998). - Contributions à l'étude géographique des frontières ; le cas de la Hongrie, Revue Géographique de l'Est, Tome XXXVIII, nº 4, p. 159-168.

Schreiber T. (1988). - La permanence du problème national en Europe centrale et orientale, Hérodote, $\mathrm{n}^{\circ} 48$, p. 69-77.

\section{NOTES}

1. Région connue sous le nom de Subcarpatie sous domination hongroise (avant 1920 et entre 1939 et 1944) et de Ruthénie sous domination tchécoslovaque, entre 1920 et 1939.

2. Székely en hongrois : désigne les Hongrois de Transylvanie.

3. Régions qui correspondent aujourd'hui au Nord de la Serbie (Voïvodine) et au nord-est de la Croatie.

4. Événement connu en France comme la révolution de 1848.

5. Roumanie, Tchécoslovaquie et Yougoslavie, alors appelée Royaume des Serbes, Croates et Slovènes. 
6. Ces 5 villes sont aujourd'hui en Slovaquie.

7. Aujourd'hui en Ukraine transcarpatique.

8. En Ruthénie, alors devenue Ukraine transcarpatique et soviétique.

9. Alliance appuyée par la France et réunissant pendant l'Entre-deux-guerres, la Pologne, la Tchécoslovaquie, la Yougoslavie et la Roumanie, unies par la crainte du révisionnisme hongrois.

\section{RÉSUMÉS}

Cet article traite de l'évolution du territoire ethnique hongrois au sein du bassin des Carpates durant 1100 années. Il s'appuie sur six dates fondamentales de l'Histoire hongroise (896, 1526, $1711,1849,1920,1944)$ permettant de distinguer 6 étapes dans le peuplement hongrois du bassin des Carpates.

Situé aux confins des mondes chrétien et musulman, des mondes slaves et germaniques, au contact avec les chrétientés d'orient et d'occident, le peuple hongrois a connu tout au long de ce millénaire des transgressions et régressions spatiales très importantes, telles que seuls les peuples polonais et croate ont pu connaître au cours de leur histoire. L'article montre l'influence de l'environnement géographique, du style de vie, du potentiel démographique et de la position politique de la Nation hongroise dans la détermination de la taille de son territoire. Il insiste enfin sur les rapports entre les frontières ethnolinguistiques de la Nation hongroise et les frontières politiques de l'État hongrois, particulièrement modifiées au XX $\mathrm{X}^{\mathrm{e}}$ siècle.

This article traces the evolution of the Hungarian ethnic area during the past 1100 years, based on six key dates $(896,1526,1711,1849,1920,1944)$ separating six stages in the Hungarian settlement of the Carpathian basin. Situated on the boundary between Christian and Muslim worlds, Slavic and Germanic world and at the junction of eastern and western Christian traditions, the Hungarian people have experienced, throughout this millennium, very important spatial expansions and contractions, probably only similarly experienced by the Croatian and Polish peoples. The article charts the influence of the geographical environment, of lifestyle, of demographic potential and of the political position of the Hungarian nation in the determination of the side of its territory. Lastly it stresses the relationship between the ethno-linguistic frontiers of the Hungarian nation and the political frontiers of the Hungarian state, particularly modified in the twentieth century.

Der Artikel behandelt die Entwicklung des ungarischen ethnischen Territoriums im inneren des Karpatenbeckens während tausend Jahren. Er stützt sich auf sechs grundlegende Daten (896, 1526, 1711, 1849, 1920, 1944), nach denen sechs Abschnitte in der ungarischen Bevölkerung des Karpatenbeckens unterschieden werden können. Gelegen an den Grenzen der christlichen und islamischen, des slawischen und germanischen Welt, im Kontakt mit der östlichen und westlichen Christenheit hat das ungarische Volk während diesem Jahrtausend bedeutende räumliche Trans- und Regressionen erlebt, wie sie nur das polnische und das kroatische Volk im Lauf ihrer Geschichte erlebt haben. Der Artikel zeigt den Einfluss der geographischen Umwelt, des Lebensstils, des demographischen Potentials und der politischen Lage der ungarischen Nation in den Grenzen ihres Territorium. Schließlich betont der Artikel die Beziehungen zwischen den ethnolinguistischen Grenzen der ungarischen Nation und den politischen Grenzen des ungarischen Staats, die sich besonders in 20. Jahrhundert veräderten. 
INDEX

Keywords : Carpathian basin, ethnic geography, Hungary, political geography

Mots-clés : bassin des Carpates, géographie ethnique, géographie politique, Hongrie

Schlüsselwörter : Bevölkerungsgeographie, Karpatenbecken, Politische Geographie, Ungarn

\section{AUTEUR}

\section{KÁROLY KOCSIS}

Département de géographie humaine - Institut de recherche en géographie - Académie des sciences de Hongrie - 62, boulevard Andrássy - H-1388 Budapest, HONGRIE 